\title{
Fatty acid transport across the cell membrane: Regulation by fatty acid transporters
}

Citation for published version (APA):

Schwenk, R. W., Holloway, G. P., Luiken, J. J. F. P., Bonen, A., \& Glatz, J. F. C. (2010). Fatty acid transport across the cell membrane: Regulation by fatty acid transporters. Prostaglandins Leukotrienes and Essential Fatty Acids, 82(4-6), 149-154. https://doi.org/10.1016/j.plefa.2010.02.029

Document status and date:

Published: 01/01/2010

DOI:

10.1016/j.plefa.2010.02.029

Document Version:

Publisher's PDF, also known as Version of record

Document license:

Taverne

Please check the document version of this publication:

- A submitted manuscript is the version of the article upon submission and before peer-review. There can be important differences between the submitted version and the official published version of record.

People interested in the research are advised to contact the author for the final version of the publication, or visit the DOI to the publisher's website.

- The final author version and the galley proof are versions of the publication after peer review.

- The final published version features the final layout of the paper including the volume, issue and page numbers.

Link to publication

\footnotetext{
General rights rights.

- You may freely distribute the URL identifying the publication in the public portal. please follow below link for the End User Agreement:

www.umlib.nl/taverne-license

Take down policy

If you believe that this document breaches copyright please contact us at:

repository@maastrichtuniversity.nl

providing details and we will investigate your claim.
}

Copyright and moral rights for the publications made accessible in the public portal are retained by the authors and/or other copyright owners and it is a condition of accessing publications that users recognise and abide by the legal requirements associated with these

- Users may download and print one copy of any publication from the public portal for the purpose of private study or research.

- You may not further distribute the material or use it for any profit-making activity or commercial gain

If the publication is distributed under the terms of Article $25 \mathrm{fa}$ of the Dutch Copyright Act, indicated by the "Taverne" license above, 


\title{
Fatty acid transport across the cell membrane: Regulation by fatty acid transporters
}

\author{
Robert W. Schwenk ${ }^{\mathrm{a}}$, Graham P. Holloway ${ }^{\mathrm{b}}$, Joost J.F.P. Luiken ${ }^{\mathrm{a}}$, Arend Bonen ${ }^{\mathrm{b}}$, Jan F.C. Glatz ${ }^{\mathrm{a}, *}$ \\ a Department of Molecular Genetics, Cardiovascular Research Institute Maastricht (CARIM), Maastricht University, P.O. Box 616, NL-6200 MD Maastricht, The Netherlands \\ ${ }^{\mathrm{b}}$ Department of Human Health \&' Nutritional Sciences, University of Guelph, Guelph, Ontario, Canada
}

\begin{abstract}
A B S T R A C T
Transport of long-chain fatty acids across the cell membrane has long been thought to occur by passive diffusion. However, in recent years there has been a fundamental shift in understanding, and it is now generally recognized that fatty acids cross the cell membrane via a protein-mediated mechanism. Membrane-associated fatty acid-binding proteins ('fatty acid transporters') not only facilitate but also regulate cellular fatty acid uptake, for instance through their inducible rapid (and reversible) translocation from intracellular storage pools to the cell membrane. A number of fatty acid transporters have been identified, including $\mathrm{CD} 36$, plasma membrane-associated fatty acid-binding protein $\left(\mathrm{FABP}_{\mathrm{pm}}\right)$, and a family of fatty acid transport proteins (FATP1-6). Fatty acid transporters are also implicated in metabolic disease, such as insulin resistance and type-2 diabetes. In this report we briefly review current understanding of the mechanism of transmembrane fatty acid transport, and the function of fatty acid transporters in healthy cardiac and skeletal muscle, and in insulin resistance/type2 diabetes. Fatty acid transporters hold promise as a future target to rectify lipid fluxes in the body and regain metabolic homeostasis.
\end{abstract}

(c) 2010 Elsevier Ltd. All rights reserved.

\section{Introduction}

The solubility of long-chain fatty acids in aqueous solutions is extremely low, i.e., in the range of 1-10 nM [1]. The presence of proteins with the ability to bind fatty acids (for convenience used to designate 'long-chain fatty acids') dramatically increases the total amount of fatty acids that can be present in the aqueous phase. For instance, albumin occurs in plasma and interstitium at a concentration of $300-600 \mu \mathrm{M}$ and can accommodate up to 1-2 mM fatty acids [2]. Likewise, cytoplasmic fatty acid-binding protein $\left(\mathrm{FABP}_{\mathrm{c}}\right)$ is abundantly present in the soluble cytoplasm of cells with an active fatty acid metabolism and can accommodate up to $150-300 \mu \mathrm{M}$ fatty acids [3,4]. As a result, albumin and $\mathrm{FABP}_{\mathrm{c}}$ act as extracellular and intracellular buffers, respectively, for fatty acids (Fig. 1). Consistent with this, the average concentration of (non-protein bound) fatty acids in plasma from healthy subjects

\footnotetext{
Abbreviations: $\mathrm{FABP}_{\mathrm{c}}$, cytoplasmic fatty acid-binding protein; $\mathrm{FABP}_{\mathrm{pm}}$, plasma membrane fatty acid-binding protein; FATP, fatty acid transport protein; GLUT4, glucose transporter-4; ACS, acyl-CoA synthetase; CPT, carnitine palmitoyltransferase; AMPK, AMP-activated kinase

* Corresponding author. Tel.: +31 43388 1208, +31 43388 1998; fax: + 31433884574 .

E-mail address: glatz@gen.unimaas.nl (J.F. Glatz).
}

was found to be $7.5 \pm 2.5 \mathrm{nM}$ [5], indicating that of the total amount of fatty acids in plasma only $<1$ part in $10^{5}$ is present in the aqueous phase.

The above data also indicate that under normal physiological conditions, with a total plasma fatty acid concentration of $100-400 \mu \mathrm{M}$ and a total cytosolic fatty acid concentration $<50 \mu \mathrm{M}$, both albumin and $\mathrm{FABP}_{\mathrm{c}}$ are in such abundance that fluctuations in their presence will hardly affect their fatty acid buffering function. Thus, studies on fatty acid uptake by hindlimb muscle from mice lacking (heart-type) $\mathrm{FABP}_{\mathrm{c}}$ showed that a $65 \%$ reduction in $\mathrm{FABP}_{\mathrm{c}}$ in heterozygous mice did not affect the rate of muscle fatty acid uptake while the full ablation of $\mathrm{FABP}_{\mathrm{c}}$ (homozygous null mice) decreased fatty acid uptake markedly [6]. This latter study illustrates that $\mathrm{FABP}_{\mathrm{c}}$ inside the cell functions as a sink for incoming fatty acids, yet plays a merely permissive action in cellular fatty acid uptake.

\section{Mechanism of transmembrane fatty acid transport}

During the preceding two decades there has been considerable discussion on the mechanism by which fatty acids enter cells, particularly whether fatty acid transport across the plasma membrane occurs by simple ('passive') diffusion, or whether fatty acid uptake is facilitated by (one or more) membrane-associated proteins (for review see $[7,8]$ ). While the various experimental 


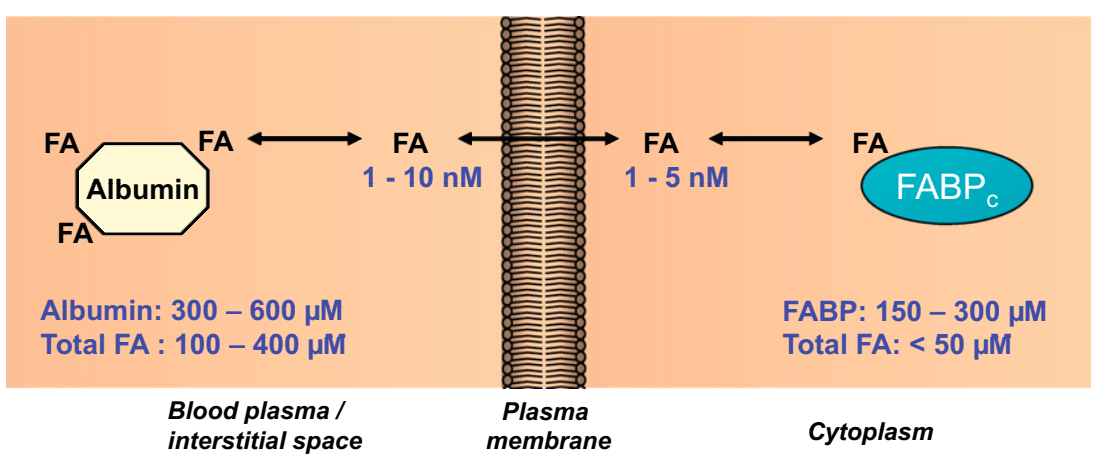

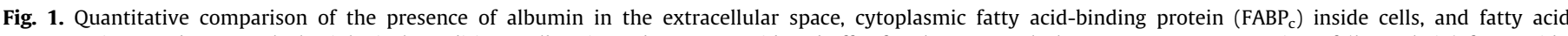

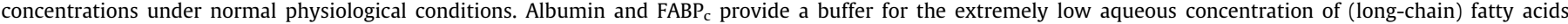

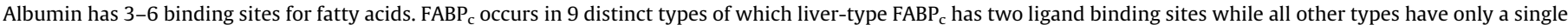
ligand binding site $[58,59]$.

studies provide support for both of these possibilities, evidence in support of a protein-mediated fatty acid uptake system is now believed to be the dominant means by which fatty acids are taken up by metabolically important tissues.

The amphipathic nature of the fatty acid molecule, with a nonpolar chain and a polar head group, provides it with the biophysical properties for entry into the phospholipid bilayer of the cell membrane. Subsequent transfer of the fatty acid from the outer leaflet of the bilayer to the inner leaflet ('flip-flop') is hampered by the charge of the polar head group. However, in the vicinity of the membrane the apparent $\mathrm{p} K_{\mathrm{a}}$ of the fatty acid shifts from about 4.5 in aqueous solutions to about 7.6 (independent of fatty acid type), as a result of which about half of the fatty acids are present in the un-ionized, i.e., protonated, form [9]. This uncharged species can then easily flip-flop to the inner leaflet of the membrane, whereafter a proton is donated to the interior solution and the fatty acid is available for desorption.

This mechanism suggests that biological membranes do not form a barrier for fatty acids. Indeed, Hamilton and co-workers have compared the permeabilities of various molecules and (longchain) fatty acids in a phospholipid bilayer to conclude that the permeability of fatty acids is several orders of magnitude larger than that of water, glucose, and other small non-electrolytes [10]. In addition, measured values of desorption kinetics revealed halftimes in the milliseconds to seconds time range for fatty acids, which is fast enough to support intracellular metabolism. Together, these data suggest that (i) fatty acids can rapidly pass phospholipid bilayers without the help of membrane proteins and (ii) membrane proteins are not needed for the purpose of releasing fatty acids into the cytosol [11].

If fatty acids could freely diffuse across biological membranes, the direction and rate of fatty acid movement would depend on fatty acid delivery to the tissue and on the transmembrane gradient of fatty acids. Such a mechanism would be difficult to control and, moreover, may not meet (changes in) metabolic demands in tissues, e.g., muscle upon the initiation of contraction. Thus, from a physiological perspective it would be highly desirable to regulate fatty acid entry into the cell, especially (i) to ensure fatty acid uptake when its extracellular concentration is low, (ii) to limit uptake when the extracellular concentration is high, (iii) to potentially select for specific fatty acid types, and (iv) to allow rapid adjustments in fatty acid provision to meet fluctuations in metabolic demands [12].

Since the early 1980s several investigators have searched for membrane-associated proteins able to bind fatty acids and that may function to facilitate and/or regulate transmembrane fatty acid transport. To date, various membrane proteins have been identified that facilitate the cellular uptake of fatty acids (Fig. 2).

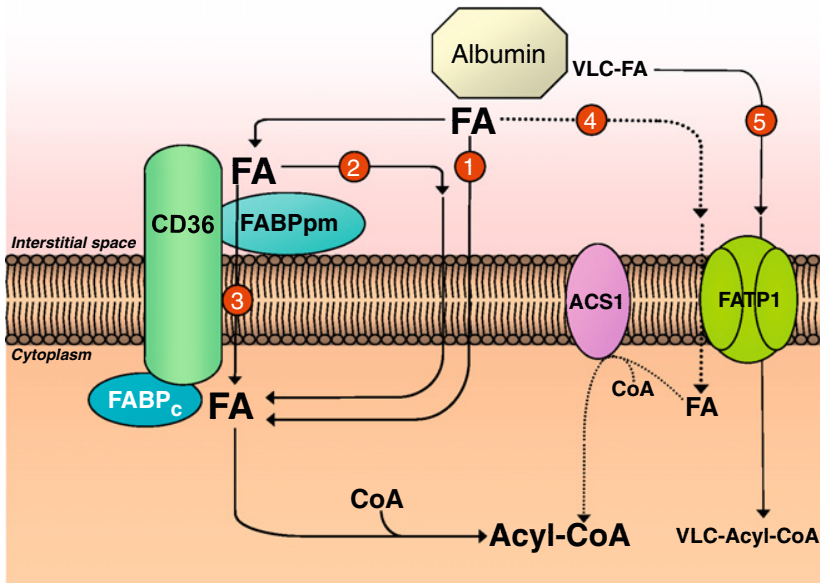

Fig. 2. Schematic representation of the current view of fatty acid transport across the cell membrane. Because the exact mechanism of transmembrane translocation of fatty acids is still unknown, different models have been suggested. (1) In view of their hydrophobic nature, fatty acids could cross the membrane by simple diffusion. (2) Alternatively, CD36 ( $88 \mathrm{kDa}$; also referred to as 'fatty acid translocase'), alone or together with the peripheral membrane protein FABP $_{\mathrm{pm}}$ (plasma membrane-associated fatty acid-binding protein; $43 \mathrm{kDa}$ ) accepts fatty acids at the cell surface to increase their local concentration and thus increase the number of fatty acid diffusion events. (3) It is also possible that CD36 itself actively transports fatty acids across the membrane. Once at the inner side of the membrane fatty acids are bound by cytoplasmic $\mathrm{FABP}\left(\mathrm{FABP}_{\mathrm{c}}\right)$ before entering metabolic or signalling pathways. (4) Additionally, a minority of fatty acids are thought to be transported by fatty acid transport proteins and rapidly activated by plasma membrane acyl-CoA synthetase (ACS1) to form acyl-CoA esters. (5) Very-longchain fatty acids $(>C 22$ ) are preferentially transported by FATPs and by action of their synthetase activity directly converted into very-long-chain acyl-CoA esters (uptake by vectorial acylation).

Adapted from [27].

For convenience, these proteins are generally referred to as 'fatty acid transporters'. The prevalent view is that these fatty acid transporters act as acceptors for fatty acids whereafter the fatty acids make their way through the cell membrane by simple diffusion (route 2 in Fig. 2). At the inner side of the membrane, the (transmembrane) proteins may provide a docking site for $\mathrm{FABP}_{\mathrm{c}}$ or for enzymes that act on fatty acids (such as acyl-CoA synthetase) (Fig. 2). Thus, these proteins may function to sequester fatty acids in the membrane, and help organize them within specific membrane domains so as to make the fatty acids readily available for subsequent aqueous transport and/or enzymatic conversion.

The membrane-associated (putative) fatty acid transporters CD36, FABP $_{\mathrm{pm}}$ and $\mathrm{FATP}_{\mathrm{s}}$ (Fig. 2) differ in molecular mass 
and degree of post-translational modification; some show a characteristic pattern of tissue distribution, while others are ubiquitously expressed. Interestingly, the FATPs form a family of 6 proteins. For most of these proteins there is evidence from studies in cell lines and/or in genetically altered animals that they facilitate cellular long-chain fatty acid uptake [13].

\section{Function of fatty acid transporters in muscle}

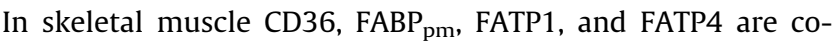
expressed. This makes this tissue suitable especially to compare the significance of the various transporters for fatty acid uptake and utilization, that is, to examine whether they all function as membrane-bound transporters and whether they channel fatty acids to specific intracellular targets, particularly oxidation and/or esterification. A recent study compared the transport efficiencies of these four proteins and their possible differential effects on fatty acid utilization in rat skeletal muscle [14]. Because knockout animals show compensatory responses in the expression of the other transporters, these animals could not be used for such studies. Instead, the genes for each of these transporters were upregulated independently in skeletal muscle only, under controlled conditions and within a physiologically meaningful range. For this, respective cDNAs cloned into plasmid DNAs were electrotransfected in the intact tibialis anterior muscle of one leg in vivo, while electrotransfection of the empty plasmid in the contralateral muscle served as control [13]. After 2 weeks, the respective fatty acid transporters were overexpressed by 1.5-2.2fold while in each case the muscle contents of the other transporters remained unchanged. All transporters increased fatty acid transport, but CD36 and FATP4 were 2.3- and 1.7-fold more effective than $\mathrm{FABP}_{\mathrm{pm}}$ and FATP1, respectively (Fig. 3, panel A) [14]. Overexpression of the transporters failed to alter the rates of fatty acid esterification into triacylglyceroles, but increased the rates of fatty acid oxidation (Fig. 3, panel B). Interestingly, the effects of CD36 and $\mathrm{FABP}_{\mathrm{pm}}$ were 3-fold greater than for FATP1 and FATP4 (Fig. 3, panel B).

Thus, at least in skeletal muscle fatty acid transporters exhibit different capacities for fatty acid transport and metabolism: in vivo CD36 and FATP4 are the most effective plasmalemmal fatty acid transporters, whereas $C D 36$ and $\mathrm{FABP}_{\mathrm{pm}}$ are key players for promoting fatty acid oxidation.

\section{Acute regulation of muscle fatty acid transport}

The presence of CD36 not only on the cell membrane but also in intracellular compartments, notably endosomes, triggered studies to identify whether regulation of fatty acid transport could occur by translocation of CD36 from endosomes to the cell membrane to increase fatty acid uptake. Such a mechanism would be analogous to the well-known regulation of glucose uptake which involves the translocation of the glucose transporter GLUT4 from an intracellular storage depot to the cell membrane. A series of studies showed that in heart and skeletal muscles both muscle contraction and insulin stimulate, within minutes, the translocation of CD36 from an endosomal compartment to the cell membrane to markedly (up to 2-fold) increase fatty acid uptake [15-17]. The contraction-induced translocation is mediated by AMP-kinase and occurs independently of the insulin-induced translocation which is mediated by PI3-kinase. In each case, both CD36 and GLUT4 are recruited in the same time frame resulting in increased uptake rates for both fatty acids and glucose $[15,18,19]$. Similar to what is known for GLUT4, the translocation of CD36 is rapid and reversible, with $\mathrm{CD} 36$ being internalized on the same time scale (minutes) as its recruitment $[15,20]$. Taken together, the regulation of fatty acid uptake by heart and muscle appears to display a striking similarity with the regulation of glucose uptake, in both cases involving the recycling of substrate transporters that is under the control of (at least a number of) the same triggers (Fig. 4).

Others have confirmed that contractile activity increases fatty acid transport via the translocation of CD36 in muscle [21]. Muscle contraction also increases the translocation to the cell membrane of $\mathrm{FABP}_{\mathrm{pm}}$, FATP1, and FATP4 [22]. Nevertheless, studies in heart and muscle obtained from CD36 knock-out animals have indicated that CD36 is fundamental to enabling the contraction-induced increase in fatty acid uptake, as its ablation almost completely blunted this increase in rate of uptake $[23,24]$.

Considerable effort is being made to unravel both the signalling and trafficking pathways involved in the recycling of CD36 in heart and muscle, in particular in relation to that of GLUT4. Knowledge on the pathways involved is relevant (i) to understand what triggers influence cellular substrate uptake through substrate transporter recycling and (ii) to learn to what extent CD36 and GLUT4 recycling share the same triggers and trafficking machinery and what signals would selectively influence either CD36-mediated fatty acid uptake or GLUT4-mediated

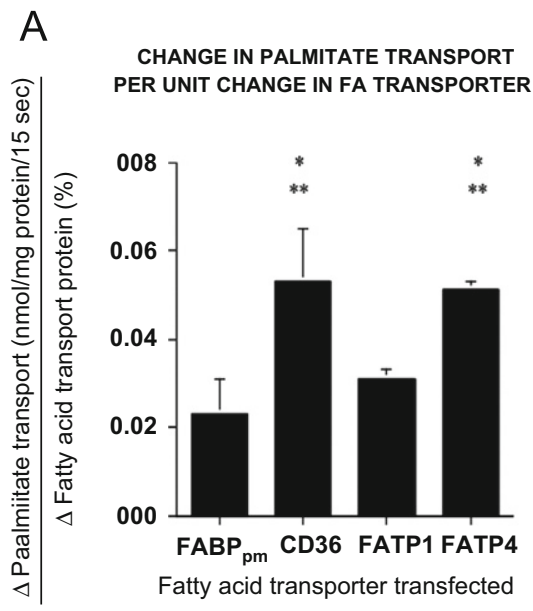

B

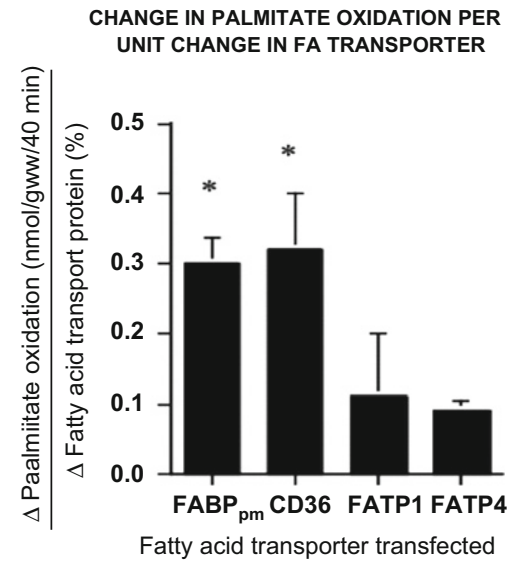

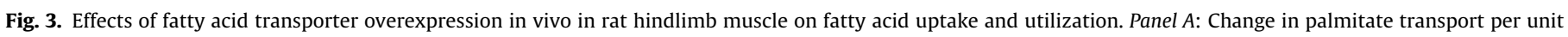
change in fatty acid transporter Panel B: Change in palmitate oxidation per unit change in fatty acid transporter.

Data reproduced, with permission, from Nickerson et al. [14]. 


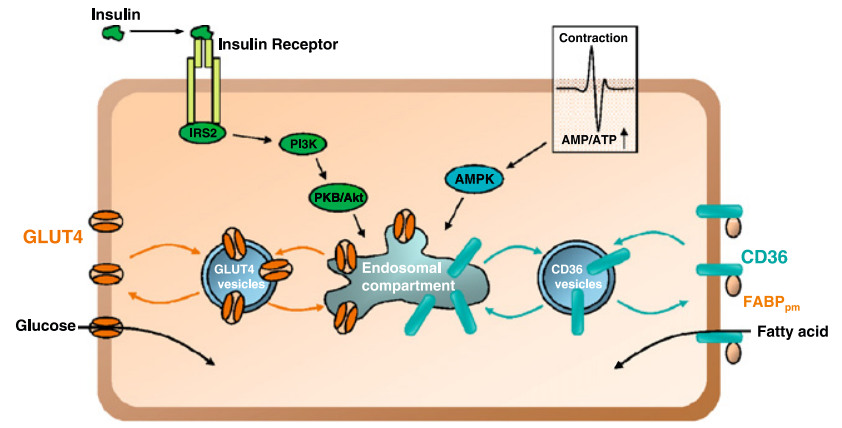

Fig. 4. Schematic representation illustrating the similarity between the regulation of cellular fatty acid uptake by CD36 translocation and that of glucose uptake by GLUT4 translocation. Both muscle contraction and insulin treatment stimulate the simultaneous recruitment of CD36 and GLUT4 from recycling endosomal storage compartments to the cell membrane to increase fatty acid and glucose uptake, respectively. AMPK, AMP-activated kinase; PI3K, PI3-kinase.

glucose uptake (which would alter substrate preference; see below). With respect to the latter, it should be noted that selective recruitment and/or internalization indeed can occur as in studies with cardiac myocytes it was observed that the phosphodiesterase inhibitor dipyridamole mobilizes CD36 from contractioninducible storage depots while not affecting GLUT4 mobilization [25], while conversely, the protein-sulfhydryl-modifying compound arsenite stimulates GLUT4-mediated glucose uptake but does not affect CD36-mediated fatty acid uptake [26]. Although the intracellular targets of these pharmacological compounds are not yet known, these data are proof of concept that selective substrate transporter recycling is possible.

So far, the signalling pathways involved in CD36 and GLUT4 recycling appear to be very much alike (reviewed in [27]). In contrast, preliminary evidence suggests that the trafficking pathways used for CD36 and for GLUT4 translocation show clear differences with respect to vesicle-associated proteins involved.

Another interesting finding is that CD36 [24,28-30] and FATP1 [30] are also present at the mitochondrial membrane, suggesting their possible involvement in mitochondrial fatty acid oxidation. A number of recent studies have shown strong support for this concept: (i) mitochondria isolated from human muscle following $2 \mathrm{~h}$ of aerobic exercise (bicycle ergometry) showed an increase in mitochondrial CD36 content which correlated with an increased rate of mitochondrial fatty acid oxidation [31], (ii) overexpression of CD36 increased mitochondrial fatty acid oxidation [30], and (iii) in CD36 knock-out animals the exercise-induced increase in fatty acid oxidation is ablated [24]. These findings suggest that CD36 translocation (from an as yet unidentified storage pool) to the mitochondria is essential to increase fatty acid oxidation during exercise. The precise mechanism by which CD36 and FATP1 facilitate mitochondrial fatty acid oxidation remains to be elucidated.

\section{Trafficking machinery involved in membrane transporter translocation}

At present little is known about the mechanisms by which fatty acid transporters travel between different intracellular compartments. However, much effort has been made to unravel proteins involved in the trafficking events responsible for the migration of the glucose transporter GLUT4 from intracellular storage compartments to the cell membrane and vice versa. During recent years evidence has accumulated that the trafficking machinery of CD36 might be closely related to that of GLUT4. For example, morphological studies in Chinese Hamster ovary cells revealed that GLUT4 and CD36 are shifted to the same microdomains in the plasma membrane upon insulin stimulation [20]. Additionally, the recycling of both GLUT4 and CD36 back into their distinct intracellular storage compartments is dependent on the action of the Rab-GTPase Rab11a [32]. Therefore, our current knowledge about GLUT4 trafficking could give links to gain further insight into the trafficking machinery of fatty acid transport proteins like CD36.

One crucial step in insulin-mediated GLUT4 translocation is the inhibition of AS160 by Akt. AS160 acts as a Rab-GTPase activating protein (Rab-GAP) and restrains GLUT4 in its storage compartment in the basal state [33]. It does so by promoting the inactive form of different Rab-GTPases known to be involved in insulin stimulated GLUT4 translocation [34,35]. Whether AS160 also functions in insulin-induced translocation of fatty acid transporters is currently not known. Interestingly, AS160 has been shown to also be a substrate of AMPK. The inhibition of AS160 by AMPK is important to stimulate glucose uptake during increased contractions, and occurs additive to the inhibition by insulin [36].

Another family of trafficking proteins that are currently under study are soluble $N$-ethylmaleimide-sensitive factor attachment protein receptors (SNARES). These proteins are present at the transport vesicle ( $\mathrm{v}$-SNAREs) and at the target membrane ( $\mathrm{t}$-SNAREs), and are mediators of membrane fusion (reviewed in [37]). This process is highly selective as a v-SNARE only interacts with a specific subset of t-SNAREs to form a SNARE complex that initiates fusion. For example, the insulin-responsive GLUT4 pool is enriched with the v-SNARE VAMP2 [38]. At the plasma membrane, VAMP2 interacts with the t-SNAREs syntaxin 4 and SNAP23 to initiate membrane fusion [39]. A negative regulator of this complex formation is Munc18c, which masks the SNAP23 interaction site on syntaxin 4 and is moved aside upon insulin stimulation [40]. In contrast to Munc18c, binding of DOC2B to syntaxin4 promotes SNARE complex formation and fusion of GLUT4 vesicles with the plasma membrane [41].

It is likely that similar mechanisms are involved in the translocation of $\mathrm{CD} 36$ upon insulin stimulation or the translocation of CD36, FABP ${ }_{\mathrm{pm}}$, FATP1, and FATP4 upon increased muscle contraction.

\section{Fatty acid transporters in pathological states}

Whole-body lipid homeostasis requires a fine tuning of fatty acid transport and utilization by metabolically active tissues. Because of their facilitary and regulatory roles in cellular fatty acid uptake and utilization, membrane fatty acid transporters form an integral part of this homeostatic system. As a result, aberrations in lipid metabolism likely will influence the functioning of fatty acid transporters, while changes in fatty acid transporter content or functioning - for instance as induced by dietary or pharmacological interventions - may have an impact on whole-body lipid metabolism and potentially elicit a pathological state.

In the last few years most attention has been given towards examining a possible role for fatty acid transporters in insulin resistance and type- 2 diabetes because these are associated with marked changes in lipid metabolism, including increased plasma fatty acid concentrations [42] and increased intramuscular triacylglycerol depots [43]. Excessive accumulation of intramyocellular fatty acids and their metabolites is commonly referred to as lipotoxicity, and is a main contributor to the pathophysiology of insulin resistance and dysfunctioning of heart and skeletal muscle $[44,45]$.

In animal models of insulin resistance [46-49] and in humans with insulin resistance and type-2 diabetes [50] it was found that the intramuscular triacylglycerol accumulation is associated with an 
increased presence of CD36 at the sarcolemma. The latter is not due to an increase in total tissue CD36 content, but rather to a permanent relocalization of this transporter to the cell membrane. Further studies in rat heart [48] and skeletal muscle (A. Bonen et al., unpublished data) have elucidated that this permanent relocalization is an early event in the development of insulin resistance and its progression towards diabetic cardiomyopathy, and, importantly, appears to precede a change in glucose uptake. These combined observations suggest that early in the development of insulin resistance alterations occur in the signalling and/or trafficking proteins specifically dedicated to CD36 recycling, which would result in a selective and permanent relocation of CD36 to the sarcolemma, without a concurrent change in the subcellular distribution of GLUT4. The increased sarcolemmal CD36 abundance, together with an increased plasma fatty acid concentration, would elicit an increased rate of fatty acid uptake to an excessive level, in turn leading to an increased rate of fatty acid esterification into triacylglycerols and increased concentrations of fatty acid metabolites such as diacylglycerols and ceramides, as has been shown recently [49]. The latter compounds then will interfere with insulininduced GLUT4 translocation to the sarcolemma so that GLUT4 is retained intracellularly and the rate of glucose uptake is lowered (i.e., insulin resistance). Thus, in this scenario, based on our studies in heart and skeletal muscle, it appears that CD36 can be regarded as a key factor in the development of insulin resistance in cardiac and skeletal muscle [51].

\section{Conclusions and remaining issues}

Although long-chain fatty acids can move across the cell membrane by simple ('passive') diffusion, consensus is beginning to appear that fatty acid-binding membrane proteins fulfil both a facilatory and a regulatory role in the process of cellular fatty acid uptake. In general, these membrane-associated proteins function as acceptors for fatty acids, assist in organizing fatty acids within membrane microdomains, and provide a site for desorption of fatty acids for subsequent binding to carrier proteins in the aqueous solution. Fatty acid transport across the cell membrane thus appears to be a highly regulated process, involving various membrane proteins (many of which are co-expressed in the same tissue) which operate through several levels of regulation such as the above-mentioned translocation from intracellular storage sites to the cell membrane, but also by post-translational modification (phosphorylation, palmitoylation, glycosylation) and possibly protein-protein interactions (reviewed in [12,5254]). The membrane fatty acid transporters are now also implicated in metabolic disease, particularly insulin resistance and its progression to type- 2 diabetes. As a corollary, fatty acid transporters are being regarded as a promising therapeutic target to re-direct lipid fluxes in the body in an organ-specific fashion. The potential of such an approach is illustrated by the observation that myocardial lipotoxicity and myocardial dysfunction induced experimentally by PPAR $\alpha$ overexpression could be rescued by ablation of CD36 [55]. However, many aspects of the mechanisms by which these fatty acid transporters function still need to be uncovered in order to design therapies to selectively manipulate their actions. These remaining issues include:

- further disclosing the signalling and trafficking pathways involved in recycling of fatty acid transporters, especially in relation to that of the glucose transporter GLUT4;

- establishing whether protein-protein interaction and posttranslational modifications among fatty acid transporters have functional significance, and whether these aspects are changed in the pathological state;
- unraveling the role of membrane microdomains (caveolae, rafts) in the functioning of fatty acid transporters;

- examining whether, and if so, in what manner, fatty acid transporters select for specific fatty acid types and/or target fatty acids towards specific metabolic pathways (oxidation, esterification) or signalling routes (activation of fatty acid responsive genes).

Fatty acid uptake has been studied mostly in heart, muscle, and adipose tissue. Uptake of fatty acids by the brain is less well addressed, despite the fact that brain expresses CD36, FATP1, FATP4 and several FABP isoforms [56,57]. It would be of much interest to study whether these latter proteins are involved in the special fatty acid handling that occurs in brain, for instance, whether these proteins are involved in the preferential and very high rates of uptake of the $\omega-3$ fatty acids (eicosapentaenoic acid and docosahexaenoic acid) during brain development.

\section{Acknowledgements}

The authors have no conflicts of interest regarding this work. The authors' studies have been supported by the Netherlands Organization for Health Research and Development (NWOZonMw Grant 912-04-075), the European Commission (Integrated Project LSHM-CT-2004-005272, Exgenesis), the Natural Sciences and Engineering Research Council of Canada, the Heart and Stroke Foundation of Ontario, the Canadian Institutes of Health Research, and the Canada Research Chair Program.

\section{References}

1] H. Vorum, R. Brodersen, U. Kragh-Hansen, A.O. Pedersen, Solubility of longchain fatty acids in phosphate buffer at $\mathrm{pH}$ 7.4, Biochim. Biophys. Acta 1126 (2) (1992) 135-142.

[2] G.V. Richieri, A. Anel, A.M. Kleinfeld, Interactions of long-chain fatty acids and albumin: determination of free fatty acid levels using the fluorescent probe ADIFAB, Biochemistry 32 (29) (1993) 7574-7580.

[3] M.M. Vork, J.F. Glatz, G.J. Van Der Vusse, On the mechanism of long chain fatty acid transport in cardiomyocytes as facilitated by cytoplasmic fatty acidbinding protein, J. Theor. Biol. 160 (2) (1993) 207-222.

[4] G.V. Richieri, R.T. Ogata, A.M. Kleinfeld, Equilibrium constants for the binding of fatty acids with fatty acid-binding proteins from adipocyte, intestine, heart, and liver measured with the fluorescent probe ADIFAB, J. Biol. Chem. 269 (39) (1994) 23918-23930.

[5] G.V. Richieri, A.M. Kleinfeld, Unbound free fatty acid levels in human serum, J. Lipid Res. 36 (2) (1995) 229-240.

[6] J.J. Luiken, D.P. Koonen, W.A. Coumans, et al., Long-chain fatty acid uptake by skeletal muscle is impaired in homozygous, but not heterozygous, hearttype-FABP null mice, Lipids 38 (4) (2003) 491-496.

[7] J.P. Kampf, A.M. Kleinfeld, Is membrane transport of FFA mediated by lipid, protein, or both? An unknown protein mediates free fatty acid transport across the adipocyte plasma membrane, Physiology (Bethesda) 22 (2007) 7-14.

[8] A. Bonen, A. Chabowski, J.J. Luiken, J.F. Glatz, Is membrane transport of FFA mediated by lipid, protein, or both? Mechanisms and regulation of proteinmediated cellular fatty acid uptake: molecular, biochemical, and physiological evidence, Physiology (Bethesda) 22 (2007) 15-29.

[9] F. Kamp, J.A. Hamilton, pH gradients across phospholipid membranes caused by fast flip-flop of un-ionized fatty acids, Proc. Natl. Acad. Sci. USA 89 (23) (1992) 11367-11370.

[10] F. Kamp, J.A. Hamilton, How fatty acids of different chain length enter and leave cells by free diffusion, Prostaglandins Leukot. Essent. Fatty Acids 75 (3) (2006) 149-159.

[11] J.A. Hamilton, New insights into the roles of proteins and lipids in membrane transport of fatty acids, Prostaglandins Leukot. Essent. Fatty Acids 77 (5-6) (2007) 355-361.

[12] J.F. Glatz, J.J. Luiken, A. Bonen, Membrane fatty acid transporters as regulators of lipid metabolism: implications for metabolic disease, Physiol. Rev. 90 (2010) 367-417

[13] D.C. Clarke, D. Miskovic, X.X. Han, et al., Overexpression of membraneassociated fatty acid binding protein (FABPpm) in vivo increases fatty acid sarcolemmal transport and metabolism, Physiol. Genomics 17 (1) (2004) 31-37.

[14] J.G. Nickerson, H. Alkhateeb, C.R. Benton, et al., Greater transport efficiencies of the membrane fatty acid transporters FAT/CD36 and FATP4 compared with 
FABPpm and FATP1 and differential effects on fatty acid esterification and oxidation in rat skeletal muscle, J. Biol. Chem. 284 (24) (2009) 16522-16530.

[15] A. Bonen, J.J. Luiken, Y. Arumugam, J.F. Glatz, N.N. Tandon, Acute regulation of fatty acid uptake involves the cellular redistribution of fatty acid translocase, J. Biol. Chem. 275 (19) (2000) 14501-14508.

[16] J.J. Luiken, D.P. Koonen, J. Willems, et al., Insulin stimulates long-chain fatty acid utilization by rat cardiac myocytes through cellular redistribution of FAT/CD36, Diabetes 51 (10) (2002) 3113-3119.

[17] J.J. Luiken, S.L. Coort, J. Willems, et al., Contraction-induced fatty acid translocase/CD36 translocation in rat cardiac myocytes is mediated through AMP-activated protein kinase signaling, Diabetes 52 (7) (2003) 1627-1634.

[18] J.J. Luiken, J. Willems, G.J. van der Vusse, J.F. Glatz, Electrostimulation enhances FAT/CD36-mediated long-chain fatty acid uptake by isolated rat cardiac myocytes, Am. J. Physiol. Endocrinol. Metab. 281 (4) (2001) E704-E712.

[19] H.K. Karlsson, A.V. Chibalin, H.A. Koistinen, et al., Kinetics of GLUT4 trafficking in rat and human skeletal muscle, Diabetes 58 (4) (2009) 847-854.

[20] M.M. van Oort, J.M. van Doorn, A. Bonen, et al., Insulin-induced translocation of CD36 to the plasma membrane is reversible and shows similarity to that of GLUT4, Biochim. Biophys. Acta 1781 (1-2) (2008) 61-71.

[21] L.P. Turcotte, M.A. Raney, M.K. Todd, ERK1/2 inhibition prevents contractioninduced increase in plasma membrane FAT/CD36 content and FA uptake in rodent muscle, Acta Physiol. Scand. 184 (2) (2005) 131-139.

[22] S.S. Jain, A. Chabowski, L.A. Snook, et al., Additive effects of insulin and muscle contraction on fatty acid transport and fatty acid transporters FAT/ CD36, FABPpm, FATP1, 4 and 6, FEBS Lett. 583 (13) (2009) 2294-2300.

[23] D.D. Habets, W.A. Coumans, P.J. Voshol, et al., AMPK-mediated increase in myocardial long-chain fatty acid uptake critically depends on sarcolemmal CD36, Biochem. Biophys. Res. Commun. 355 (1) (2007) 204-210.

[24] G.P. Holloway, S.S. Jain, V.S. Bezaire, et al., FAT/CD36 null mice reveal that mitochondrial FAT/CD36 is required to up-regulate mitochondrial fatty acid oxidation in contracting muscle, Am. J. Physiol. Regul. Integr. Comp. Physiol. 297 (4) (2009) R960-R967.

[25] J.J. Luiken, S.L. Coort, J. Willems, W.A. Coumans, A. Bonen, J.F. Glatz, Dipyridamole alters cardiac substrate preference by inducing translocation of FAT/CD36, but not that of GLUT4, Mol. Pharmacol. 65 (3) (2004) 639-645.

[26] J.J. Luiken, I. Momken, D.D. Habets, et al., Arsenite modulates cardiac substrate preference by translocation of GLUT4, but not CD36, independent of mitogen-activated protein kinase signaling, Endocrinology 147 (11) (2006) 5205-5216.

[27] R.W. Schwenk, J.J. Luiken, A. Bonen, J.F. Glatz, Regulation of sarcolemmal glucose and fatty acid transporters in cardiac disease, Cardiovasc. Res. 79 (2) (2008) 249-258.

[28] S.E. Campbell, N.N. Tandon, G. Woldegiorgis, J.J. Luiken, J.F. Glatz, A. Bonen, A novel function for fatty acid translocase (FAT)/CD36: involvement in long chain fatty acid transfer into the mitochondria, J. Biol. Chem. 279 (35) (2004) 36235-36241.

[29] V. Bezaire, C.R. Bruce, G.J. Heigenhauser, et al., Identification of fatty acid translocase on human skeletal muscle mitochondrial membranes: essential role in fatty acid oxidation, Am. J. Physiol. Endocrinol. Metab. 290 (3) (2006) E509-E515.

[30] D. Sebastian, M. Guitart, C. Garcia-Martinez, et al., Novel role of FATP1 in mitochondrial fatty acid oxidation in skeletal muscle cells, J. Lipid Res. (2009).

[31] G.P. Holloway, V. Bezaire, G.J. Heigenhauser, et al., Mitochondrial long chain fatty acid oxidation, fatty acid translocase/CD36 content and carnitine palmitoyltransferase I activity in human skeletal muscle during aerobic exercise, J. Physiol. 571 (Part 1) (2006) 201-210.

[32] R.W. Schwenk, J.J. Luiken, J. Eckel, FIP2 and Rip11 specify Rab11a-mediated cellular distribution of GLUT4 and FAT/CD36 in H9c2-hIR cells, Biochem. Biophys. Res. Commun. 363 (1) (2007) 119-125.

[33] L. Eguez, A. Lee, J.A. Chavez, et al., Full intracellular retention of GLUT4 requires AS160 Rab GTPase activating protein, Cell Metab. 2 (4) (2005) 263-272.

[34] H. Sano, L. Eguez, M.N. Teruel, et al., Rab10, a target of the AS160 Rab GAP, is required for insulin-stimulated translocation of GLUT4 to the adipocyte plasma membrane, Cell. Metab. 5 (4) (2007) 293-303.
[35] S. Ishikura, P.J. Bilan, A. Klip, Rabs $8 \mathrm{~A}$ and 14 are targets of the insulinregulated Rab-GAP AS160 regulating GLUT4 traffic in muscle cells, Biochem. Biophys. Res. Commun. 353 (4) (2007) 1074-1079.

[36] H.F. Kramer, C.A. Witczak, N. Fujii, et al., Distinct signals regulate AS160 phosphorylation in response to insulin AICAR, and contraction in mouse skeletal muscle, Diabetes 55 (7) (2006) 2067-2076.

[37] R. Jahn, R.H. Scheller, SNAREs_engines for membrane fusion, Nat. Rev. Mol Cell Biol. 7 (9) (2006) 631-643.

[38] L. Sevilla, E. Tomas, P. Munoz, et al. Characterization of two distinct intracellular GLUT4 membrane populations in muscle fiber. Differentia protein composition and sensitivity to insulin, Endocrinology 138 (7) (1997) 3006-3015.

[39] M. Kawanishi, Y. Tamori, H. Okazawa, S. Araki, H. Shinoda, M. Kasuga, Role of SNAP23 in insulin-induced translocation of GLUT4 in 3T3-L1 adipocytes. Mediation of complex formation between syntaxin4 and VAMP2, J. Biol. Chem. 275 (11) (2000) 8240-8247.

[40] Y. Tamori, M. Kawanishi, T. Niki, et al., Inhibition of insulin-induced GLUT4 translocation by Munc18c through interaction with syntaxin4 in 3T3-L1 adipocytes, J. Biol. Chem. 273 (31) (1998) 19740-19746.

[41] N. Fukuda, M. Emoto, Y. Nakamori, et al. DOC2B: a novel syntaxin-4 binding protein mediating insulin-regulated GLUT4 vesicle fusion in adipocytes, Diabetes 58 (2) (2009) 377-384.

[42] G. Boden, X. Chen, N. Iqbal, Acute lowering of plasma fatty acids lowers basa insulin secretion in diabetic and nondiabetic subjects, Diabetes 47 (10) (1998) 1609-1612.

43] D.A. Pan, S. Lillioja, A.D. Kriketos, et al., Skeletal muscle triglyceride levels are inversely related to insulin action, Diabetes 46 (6) (1997) 983-988.

[44] R.H. Unger, Lipotoxic diseases, Annu. Rev. Med. 53 (2002) 319-336.

[45] W.L. Holland, T.A. Knotts, J.A. Chavez, L.P. Wang, K.L. Hoehn, S.A. Summers, Lipid mediators of insulin resistance, Nutr. Rev. 65 (6, Part 2) (2007) S39-S46.

[46] J.J. Luiken, Y. Arumugam, D.J. Dyck, et al., Increased rates of fatty acid uptake and plasmalemmal fatty acid transporters in obese Zucker rats, J. Biol. Chem. 276 (44) (2001) 40567-40573.

[47] S.L. Coort, D.M. Hasselbaink, D.P. Koonen, et al., Enhanced sarcolemmal FAT CD36 content and triacylglycerol storage in cardiac myocytes from obese Zucker rats, Diabetes 53 (7) (2004) 1655-1663.

48] D.M. Ouwens, M. Diamant, M. Fodor, et al., Cardiac contractile dysfunction in insulin-resistant rats fed a high-fat diet is associated with elevated CD36mediated fatty acid uptake and esterification, Diabetologia 50 (9) (2007) 1938-1948.

[49] G.P. Holloway, C.R. Benton, K.L. Mullen, et al., In obese rat muscle transport of palmitate is increased and is channeled to triacylglycerol storage despite an increase in mitochondrial palmitate oxidation, Am. J. Physiol. Endocrinol Metab. 296 (4) (2009) E738-E747.

[50] A. Bonen, M.L. Parolin, G.R. Steinberg, et al., Triacylglycerol accumulation in human obesity and type 2 diabetes is associated with increased rates of skeletal muscle fatty acid transport and increased sarcolemmal FAT/CD36, FASEB J. 18 (10) (2004) 1144-1146.

[51] J.F. Glatz, A. Bonen, D.M. Ouwens, J.J. Luiken, Regulation of sarcolemma transport of substrates in the healthy and diseased heart, Cardiovasc. Drugs Ther. 20 (6) (2006) 471-476.

[52] X. Su, N.A. Abumrad, Cellular fatty acid uptake: a pathway under construction, Trends Endocrinol. Metab. 20 (2) (2009) 72-77.

[53] H. Doege, A. Stahl, Protein-mediated fatty acid uptake: novel insights from in vivo models, Physiology (Bethesda) 21 (2006) 259-268.

[54] M. Febbraio, R.L. Silverstein, CD36: implications in cardiovascular disease, Int. J. Biochem. Cell Biol. 39 (11) (2007) 2012-2030.

[55] J. Yang, N. Sambandam, X. Han, et al., CD36 deficiency rescues lipotoxic cardiomyopathy, Circ. Res. 100 (8) (2007) 1208-1217.

[56] R.W. Mitchell, C.L. Edmundson, D.W. Miller, G.M. Hatch, On the mechanism of oleate transport across human brain microvessel endothelial cells, J. Neurochem. 110 (3) (2009) 1049-1057.

[57] Y. Owada, Fatty acid binding protein: localization and functional significance in the brain, Tohoku J. Exp. Med. 214 (3) (2008) 213-220.

[58] J.F. Glatz, J. Storch, Unravelling the significance of cellular fatty acid-binding proteins, Curr. Opin. Lipidol. 12 (3) (2001) 267-274.

[59] J. Storch, B. Corsico, The emerging functions and mechanisms of mammalian fatty acid-binding proteins, Annu. Rev. Nutr. 28 (2008) 73-95. 